\title{
Oral Health is Cost-Effective to Maintain but Costly to Ignore
}

Y oneyama et al. ${ }^{1}$ have demonstrated the role of a familiar, straightforward intervention-providing regular oral hygiene care-on reducing the incidence of pulmonary disease in institutionalized older people. Pneumonia, "the old man's friend," is a leading cause of death in nursing home residents and among the most common cause of hospitalizations in this group. ${ }^{2}$ In the nursing home setting, pneumonia may account for as many as $48 \%$ of the infections, with mortality as high as $44 \% .^{3}$ As such, pneumonia is a prominent contributor to the climbing costs of long-term care in older persons in the developed world. Employing data reported by Muder ${ }^{2}$ that the median rate of nursing home-acquired hospitalization for pneumonia is one case per 1,000 patient days and from Dempsey ${ }^{4}$ that the average cost of such a hospitalization is approximately $\$ 14,000$ (in 1993 dollars), the annual cost of nursing home-acquired pneumonia among the 1.5 million nursing home residents in the United States easily exceeds $\$ 8$ billion. The data of Yoneyama et al. support the use of modest resources for the provision of daily oral care to avoid these substantial healthcare costs and the increased mortality and morbidity associated with pneumonia.

Epidemiological studies have demonstrated that not only medical but also dental/oral diseases are risk factors for the development of aspiration pneumonia. In multiple logistic regression analyses, medical factors identified included needing help feeding, diabetes mellitus, and chronic obstructive pulmonary disease. Oral risk factors included increased numbers of decayed teeth, presence of decaycausing organisms, and presence of periodontal diseaseassociated dental plaque organisms. ${ }^{5}$

It has long been suspected that pneumonia is related to oral pathogens. The infection of the lung via aspiration of oral pathogens, particularly anaerobic organisms, was investigated by Finegold who verified the presence of anaerobes in transtracheal aspirates. ${ }^{6}$ The link between oral pathogens and respiratory infection has been discussed in a number of recent reviews concerning oral colonization. ${ }^{5,7-10}$ Several common oral organisms show epidemiological links to the development of pneumonia. ${ }^{11}$ Colonization of the oral cavity in older persons, especially those in nursing homes, includes nosocomial pathogenic organisms such as Staphylococcus aureus,,${ }^{11}$ yeast,,${ }^{12,13}$ and enteric gram-negative bacili. ${ }^{11,13-16}$ Such colonization is particularly prevalent in older persons who are in medical intensive care. ${ }^{14}$

Correlations between pneumonia and the presence of pathogens associated with natural teeth raise particular concern because a dramatically increasing proportion of older Americans, and therefore of nursing home residents, is retaining a growing proportion of their teeth into old age. The National Center for Health Statistics reported in 1957 that $68 \%$ of Americans aged 75 and older were edentulous (had no remaining natural teeth), ${ }^{17}$ but the $\mathrm{Na}$ tional Institute for Dental Research reported in 1986 that this figure had dropped to below $40 \% .{ }^{18}$ More-recent regional studies ${ }^{19}$ support the observation that this trend for increasing tooth retention in older people has continued. The presence of even a single natural tooth puts an individual at risk for the diseases associated with the presence of teeth, such as decay and periodontal disease.

Self-care impairment is endemic in the nursing home population, virtually by definition. Even in healthy seniors, effective daily oral hygiene is commonly complicated by one or more of a host of factors, including impaired visual acuity; diminished manual dexterity; arthritic conditions affecting grip strength and range of motion in the wrist, elbow, and shoulder; decreased salivary flow rate and impaired salivary buffering capacity secondary to a broad variety of drugs and diseases; increased surface area of teeth and the exposure of dental roots due to prior periodontal disease; and the presence of permanent and removable dental prostheses replacing missing teeth. ${ }^{20} \mathrm{~A}$ growing proportion of older persons in nursing homes possesses natural teeth and is therefore subject to all of these impairments to effective daily hygiene. In addition, members of this group may be expected to be partially or fully dependent on nurses' aides for self-care activities, and it has been widely documented that aides typically place a low priority on oral health (both for themselves and for their patients), receive little to no rebuke if oral care is overlooked, have multiple other tasks that do invoke a reaction if omitted, express distaste for the task on a continuum of descriptions that range from unpleasant to dangerous, and receive little to no training in its provision. ${ }^{21}$ Because the few regulations about oral care are often unenforced, ${ }^{22}$ there is little motivation to play any role in residents' daily oral care regimens.

The suggestion has been made that specific aides be trained and assigned to provide oral care, to the exclusion of other responsibilities. There are indications that such training could be effective, ${ }^{23}$ but the model is generally viewed as incurring additional, unnecessary expense. The work by Yoneyama et al. opens the door to demonstrating the merits of such an approach, and the fallacy of characterizing it as additional expense, for to do so would overlook the potential cost savings. For instance, in the United States there are approximately 19,000 nursing homes. If each hired a nurses' aide to do nothing but perform oral hygiene, and each was paid (with benefits) $\$ 25,000$ annually, the total cost would be under $\$ 500$ million. If the rate 
of pneumonia were decreased by only $10 \%$ through this intervention, the savings would be over $\$ 800$ million annually, with a net benefit of over $\$ 300$ million-and the preliminary figures of Yoneyama et al. reflect a likely decrease in disease rate three times this magnitude.

The article raises a few questions. For instance, the authors employed several measures for the oral hygiene intervention, including brush and dentifrice, povidone iodine Betadine $^{\circledR}$ scrubs, and weekly professional cleanings. Might the results have been the same with any of these alone, or any two? In the United States, povidon iodine Betadine ${ }^{\circledR}$ has low acceptability among patients, but other oral hygiene rinses, such as chlorhexidine $0.12 \%$, have been shown to be effective disinfectants in vitro. ${ }^{24,25}$ This antiseptic formulation has shown some clinical promise, ${ }^{26}$ as have other forms. ${ }^{27,28}$

Yoneyama et al. also acknowledge shortcomings in their definition of pneumonia, in that much of their data are based on "febrile days" in long-term care. Not all febrile days are due to pneumonia, but many other causes, if they can be identified, can be traced back to an oral origin. A recent study that used a stricter definition of aspiration pneumonia has demonstrated significant correlations between aspiration pneumonia and dental decay and periodontal disease. ${ }^{29}$

In summary, the paper by Yoneyama et al. highlights the association between poor oral hygiene and respiratory disease at a time when persons in long-term care are retaining their teeth and generating high costs from pneumonia morbidity. The paper points to the likelihood that relatively low-cost interventions in oral hygiene could reduce some of the higher-cost outcomes of aspiration pneumonia. Although improvement in oral hygiene is not accomplished without cost, this may be an excellent goal for the improvement of long-term care quality, the reduction of undesirable outcomes, and measurable cost savings.

Margaret Terpenning, MD Ann Arbor GRECC

Ann Arbor VA Health Care System Division of Geriatric Medicine Department of Medicine University of Michigan Medical School Ann Arbor, MI

Kenneth Shay, DDS, MS Ann Arbor GRECC Ann Arbor VA Health Care System Geriatrics and Extended Care Service Line Veterans Integrated Services Network U.S. Department of Veterans Affairs Department of Periodontics/Prevention/Geriatrics University of Michigan School of Dentistry Ann Arbor, MI

\section{REFERENCES}

1. Yoneyama T, Yoshida M, Mukaiyama $\mathrm{H}$ et al. Oral care reduces pneumonia of elderly patients in nursing homes. J Am Geriatr Soc 2002;50:430-433.
2. Muder RR. Pneumonia in residents of long-term care facilities: Epidemiology, etiology, management, and prevention. Am J Med 1998;105:319-330.

3. Medina-Walpole AM, Katz PR. Nursing home-acquired pneumonia. J Am Geriatr Soc 1999;47:1005-1015.

4. Dempsey CL. Nursing home-acquired pneumonia: Outcomes from a clinical process improvement program. Pharmacotherapy 1995;15(1Pt 2):33S-38S.

5. Terpenning MS, Taylor GW, Lopatin D et al. Aspiration pneumonia: Dental and oral risk factors in an older veteran population. J Am Geriatr Soc 2001; 49:557-563.

6. Finegold SM. Aspiration pneumonia. Rev Infect Dis 1991;13:S737-S742.

7. Scannapieco FA, Papandonotos GD, Dunford RG. Association between oral conditions and respiratory disease in a national sample survey population. Ann Periodontol 1998;3:251-256.

8. Scannapieco FA, Mylotte JM. Relationships betweeen periodontal disease and bacterial pneumonia. J Periodontol 1996;67:1114-1122.

9. Limeback H. Implications of oral infections on systemic diseases in the institutionalized elderly with a special focus on pneumonia. Ann Periodontol 1998;3:262-275.

10. Taylor G, Loesche WJ, Terpenning M. Impact of oral diseases on systemic health in the elderly: Diabetes mellitus and aspiration pneumonia. J Public Health Dent 2000;60:313-320.

11. Scannapieco, FA. Role of oral bacteria in respiratory infection. J Periodontol 1999;70:793-802.

12. Dahlen G, Wikstrom M. Occurrence of enteric rods, staphylococci and candida in subgingival samples. Oral Microbiol Immunol 1995;10:42-46.

13. Slots J, Rams TE, Listgarten MA. Yeasts, enteric rods and pseudomonads in the subgingival flora of severe adult periodontitis. Oral Microbiol Immunol 1988;3:47-52.

14. Scannapieco FA, Stewart EM, Mylotte JM. Colonization of dental plaque by respiratory pathogens in medical intensive care patients. Crit Care Med 1992;20:740-745.

15. Valenti WM, Trudell RG, Bentley DW. Factors predisposing to oropharyngeal colonization with Gram-negative bacilli in the aged. N Engl J Med 1978; 298:1108-1111.

16. Johanson WG, Pierce AK, Sanford JP et al. Nosocomial respiratory infections with Gram-negative bacilli. The significance of colonization of the respiratory tract. Ann Intern Med 1972;77:701-706.

17. Shay K, Ship JA. The importance of oral health in the older patient. J Am Geriatr Soc 1995;43:1414-22.

18. Miller AJ, Brunelle JA, Carlos JP et al. Oral health of U.S. adults: The national survey of oral health in U.S. employed adults and seniors: 1985-1986 (NIH publication no. 87-2868). Washington, DC: National Institute of Dental Research, 1987.

19. Douglass CW, Jette AM, Fox $\mathrm{CH}$ et al. Oral health status of the elderly in New England. J Gerontol 1993;48:M39-M46.

20. Berkey DB, Shay K. General dental care for the elderly. Clin Geriatr Med 1992;8:579-597.

21. Chalmers JM, Levy SM, Buckwalter KC et al. Factors influencing nurses' aides' provision of oral care for nursing facility residents. Spec Care Dent 1996;16:71-79.

22. Thai PH, Shuman SK, Davidson GB. Nurses' dental assessments and subsequent care in Minnesota nursing homes. Spec Care Dent 1997;17:13-18.

23. Paulsson G, Soderfeldt B, Fridlund B et al. Recall of an oral health education programme by nursing personnel in special housing facilities for the elderly. Gerodontology 2001;18:7-14

24. Giertsen E, Guggenheim B, Thurnheer T et al. Microbiologic aspects of an insitu model to study effects of antimicrobial agents on dental plaque ecology. Eur J Oral Sci 2000;108:403-411.

25. Powell LV, Persson RE, Kiyak HA et al. Effect of a $0.12 \%$ chlorhexidine rinse on salivary lactobacilli and mutans streptococci (Abstract 988). J Dent Res 2001;80(AADR Abstracts):159.

26. Persson RE, Truelove EL, LeResche L et al. Therapeutic effects of daily or weekly chlorhexidine rinsing on oral health of a geriatric population. Oral Surg Oral Med Oral Pathol 1991;72:184-192.

27. Pitten FA, Splieth C, Kramer A. Prophylactic and therapeutic application of antimicrobial agents in the oral cavity. Pharmazie 2000;55:635-639.

28. Clark DC, Morgan J, MacEntee MI. Effects of a $1 \%$ chlorhexidine gel on the cariogenic bacteria in high-risk elders: A pilot study. Spec Care Dent 1991; 11:101-103.

29. Langmore S, Terpenning MS. Predictors of aspiration pneumonia: How important is dysphagia? Dysphagia 1998;13:69-81. 